\title{
Cultura corporal afro-brasileira na escola: resistência e perspectiva de estudantes do Ensino Médio
}

\author{
Ivan Livindo de Senna Corrêa *
}

Resumo: Este artigo tem por objetivo refletir sobre a cultura corporal e a cultura afro-brasileira, enquanto conteúdo escolar, e diagnosticar as vivências dos alunos do Ensino Médio na cultura corporal afro-brasileira. Para realizar a pesquisa aplicou-se um questionário com questões abertas e fechadas a 49 estudantes do Ensino Médio, os quais concordaram em participar da pesquisa. Como resultados constatou-se que as áreas que mais trabalham a cultura afro-brasileira na escola são História, Geografia e Sociologia. Observou-se resistência dos estudantes em optarem por atividades da cultura corporal afro-brasileira, como uma modalidade, em Educação Física. A vivência na cultura corporal dos estudantes é basicamente em esporte, dança e ginástica de origem europeia. Os estudantes apontam como perspectiva a oferta do ensino de capoeira e dança como disciplina eletiva, porém não como conteúdo da Educação Física escolar.

Palavras-chave: Cultura corporal afro-brasileira; Educação física; Ensino médio.

Abstract: This paper aims to think over body culture and Afrobrazilian culture as school subject as well diagnose the experience of high school students on Afro-brazilian body culture. It was applied a questionnaire with opened and closed questions to

Professor de Educação Física do CAp/UFRGS. Mestre em Ciência do Movimento Humano pela Universidade Federal de Santa Maria-UFSM, doutorando em Educação/UFRGS. E-mail: ivanlivindo@gmail.com 
49 high schoolers that agreed to take part on the research. As results were identified the fields which work on Afro-brazilian body culture the most: history, geography and socilogy. It was observed some resistance from the students to choose activities which evolved Afro-brazilian body culture as Physical Education activity. The students' experience on body culture is basically on sports such as dance and gymnastics from European origin. The students suggest as a proposal to provide capoeira and dance as an optative activity but not as a regular subject on Physical Education.

Keywords: Afro-brazilian body culture at school; Resistance; Perspective of high schoolers.

\section{Introdução}

A cultura corporal afro-brasileira, temática central deste trabalho, é fruto das reflexões na área da Educação Física escolar que, ao longo dos últimos 30 anos, vêm sendo aprofundada pelo campo crítico da Educação Física, no sentido de incorporar essa manifestação da cultura popular brasileira como uma atividade curricular a ser trabalhada na escola. A compreensão de cultura corporal, como objeto de estudo da Educação Física escolar, perpassa os debates teóricos da Educação Física brasileira desde a década de 1980 (SOUZA JUNIOR, 2011) e culmina com a publicação do livro Metodologia do ensino de Educação Física (SOARES et al., 1992). A obra, escrita por seis autores que se intitulam Coletivo de Autores, conceitua a Educação Física como área de conhecimento que trata de cultura corporal, manifestada em atividades como "Jogo, Esporte, Capoeira, Ginástica e Dança" (SOARES et al., 1992, p. 64). No que se refere à Capoeira, os autores apontam-na como um símbolo da luta pela emancipação do negro no Brasil escravocrata. Nesse sentido, resgatam a "capoeira enquanto manifestação cultural" e apontam-na com uma das principais atividades a ser trabalhada na Educação Física 
escolar, vinculado a sua historicidade e ao "movimento cultural e político que a gerou” (SOARES et al., 1992, p. 76).

Além desses estudos, outros trabalhos vinculados a uma Educação Física critica ${ }^{1}$, que incorporam em suas análises conhecimentos da sociologia, antropologia e filosofia, têm contribuído para a ampliação das reflexões da cultura corporal na escola. Nesse campo ampliado de reflexão crítica da Educação Física adotou-se como referência, nesse estudo, os trabalhos de Bracht (1992), Daólio (1995), Soares et al. (1992), Soares (1994), Kunz (1994; 1998) e Santin (2003). Esses pensadores, entre outros, têm suas trajetórias marcadas por reflexão e luta pela construção de Educação Física e educação que valorizem a cultura brasileira no âmbito escolar.

Observa-se que na Educação Física escolar a preocupação com a cultura afro-brasileira está presente, inicialmente, desde os anos 1980 e aumenta com o surgimento da Lei 10.639 \03, que torna obrigatório o ensino da história e cultura afro-brasileiras na escola. Com isso, crescem os debates e as experiências de inclusão da cultura afro-brasileira no meio escolar. Em 2008, a temática de inclusão cultural é ampliada e introduz-se pela Lei no 9394/96, a Lei de Diretrizes e Base da Educação Nacional (LDB), também a obrigatoriedade do ensino da cultura indígena.

Diante dos debates acadêmicos da Educação Física, referentes à construção de uma proposta curricular que atenda o ensino da cultura corporal e perante a Lei $11.645 \backslash 08$, esse artigo tem como objetivos: refletir sobre a cultura corporal e a cultura afro-brasileira como conteúdo escola, identificar os espaços e as áreas de conbecimento do Colégio de Aplicação da UFRGS que tratam da cultura afrobrasileira e diagnosticar as vivências dos alunos do Ensino Médio na cultura corporal.

1 Entende-se como Educação Física crítica os estudos que se fundamentam em bases filosóficas, antropológicas e sociológicas e que fazem uma crítica à prática da Educação Física escolar tradicional, muitas vezes, propondo estratégias pedagógicas de superação dessa realidade, no sentido que a prática da Educação Física escolar possa contribuir para a transformação social. 


\section{Metodologia}

Para o desenvolvimento da pesquisa adotou-se procedimentos metodológicos de cunho quantitativo e qualitativo. Os dados foram coletados através de um questionário com questões abertas e fechadas, aplicado aos estudantes do Ensino Médio (EM) do Colégio de Aplicação (CAp) da Universidade Federal do Rio Grande do Sul (UFRGS). Os dados obtidos com o questionário forneceram informaçóes relevantes sobre $\mathrm{o}$ aspecto das vivências, dos espaços e áreas de conhecimentos que tratam da cultura corporal afro-brasileira na escola. Segundo Foddy (1996, p. 142), as questões abertas permitem "[...] aos inquiridos expressarem exatamente o que lhe vem à cabeça sem sofrer influências de sugestôes avançadas pelo investigador”. Já as questões fechadas possibilitam referências e informações precisas de fáceis quantificações e análises.

Para a análise quantitativa dos dados utilizamos o programa SPSS 18.0 (Statistical Package for Social Sciences), que segundo Mundstock et al. (2006, p. 3), "[...] é uma ferramenta para análise de dados utilizando técnicas estatísticas básicas e avançadas". Além da análise estatística descritiva, realizamos uma análise qualitativa a qual possibilitou compreender as concepções e propostas dos estudantes, quanto ao estudo da cultura afrobrasileira na escola.

Participaram desse estudo 49 estudantes que concordaram em participar da pesquisa e que devolveram o questionário com o termo de consentimento assinados pelos pais ou responsáveis. Esses 49 estudantes fazem parte de uma população de 240 estudantes do Ensino Médio do CAp/UFRGS, representando, portanto, um percentual de $20 \%$ dos alunos do EM. 


\section{A cultura corporal na escola}

Pensar a cultura corporal na escola nos remete à história da educação física brasileira e da educação. Pode-se dizer que a Escola teve e tem um papel prioritário na dominação e inculcação de valores dominantes (SILVA, 1992). Assim, a educação física foi introduzida na escola inicialmente como um caráter "higienista" e "eugenista" e, posteriomente, "desportivista" (SOARES, 1994; BRACHT, 1992).

A Educação Física "higienista", fruto do ideal liberal positivista, procurava formar um cidadão saudável, com hábitos necessários ao trabalho industrial que respeitasse às regras sociais $\mathrm{e}$, consequentemente, se adaptasse à disciplina do trabalho fabril, em expansão nesse período. Essa educação física teve predominância no final do Século XIX e início do Século XX. A Educação Física "higienista", como instrumento republicano do período, sofreu influência militar que impõe à Educação Física escolar uma prática de caráter disciplinar. Conforme Soares (1994, p. 10), nesse período, a Educação Física “[...] encarna e expressa os gestos autoritários, disciplinadores e se faz protagonista de um corpo saudável, torna-se receita e remédio didático para curar os homens da sua letargia, indolência, preguiça e imoralidade". O discurso oficial da época vê a Educação Física como um dos principais instrumentos para afastar a juventude da vadiagem e do consumo de álcool e tabaco.

Esse mesmo ideal republicano de construir uma sociedade saudável reprimiu e marginalizou uma das principais manifestações da cultura corporal afro-brasileira, a capoeira. Marinho (1945 apud SANTOS, 2005, p. 87) afirma que o "Decreto Lei 487 de 11 de outubro de 1890" no capítulo XIII, intitulado, "Dos Vadios e Capoeiras", proibia severamente:

Art. 402 - Fazer nas ruas e praças públicas exercícios de agilidade e destreza corporal, conhecidos pela denominação de capoeiragem; andar em correrias, com armas ou instrumentos capazes de produzir uma lesão 
corporal, provocando tumulto ou desordens, ameaçando pessoa certa ou incerta ou incutindo temor ou algum mal;

Pena: De prisão celular de dois a seis meses.

Parágrafo único - É considerada circunstância agravante pertencer o capoeira a algum bando ou malta. Aos chefes ou cabeças se imporá a pena em dobro.

Art. 403 - No caso de reincidência será aplicado ao capoeira, no grau máximo a pena do art. 400 (Pena de um a três anos em colônias penais que se fundarem em ilhas marítimas, ou nas fronteiras do território nacional, podendo para esse fim serem aproveitados os presídios militares existentes).

Parágrafo único - Se for estrangeiro será deportado depois de cumprir a pena.

Art. 404 - Se nesses exercícios de capoeiragem perpetrar homicídios, praticar lesão corporal, ultrajar o pudor público e particular, e perturbar a ordem, a tranquilidade e a segurança pública ou for encontrado com armas, incorrerá cumulativamente nas penas cominadas para tais crimes.

Enquanto que a prática da ginástica de origem europeia era disseminada em todo o Brasil, práticas da cultura corporal afro-brasileira eram proibidas e criminalizadas.

Paralelo a Educação Física "higienista”, surgiu a Educação Física "eugenista”, de caráter racista e de branqueamento do povo brasileiro. Para Soares (1994), essa educação física baseava-se em estudos das ciências biológicas positivistas de época, acreditavase que deveria haver um controle da natalidade e estimular a reprodução das pessoas fortes, equilibradas, inteligentes e bonitas. Para fortalecer a raça brasileira tinha-se como remédio o controle sanitário e a prática de ginástica.

A visão "higienista" e "eugenista" da Educação Física predominaram até a Segunda Grande Guerra. A partir dos anos 1950, cresceu a influência dos esportes coletivos na Educação Física escolar, sendo o futebol, o voleibol, o handebol e o basquetebol os mais praticados. Uma observação curiosa é que esses esportes principalmente o futebol e o handebol são oriundos dos jogos populares europeus. O futebol é originário da Inglaterra e 
o handebol da Holanda. Já o basquetebol e o voleibol são jogos construídos dentro das práticas da Educação Física escolar na Associação Cristã de Moços, nos Estados Unidos da América (DUARTE, 2006). A predominância dessas atividades na Educação Física escolar perpassa até nossos dias.

Segundo estudos de Corrêa e Moro (2004) e Corrêa, Baran e Meneguizzi (2005), é praticamente inexistente o ensino da capoeira e da dança afro na escola. Quando essas aparecem, ocorrem em manifestações espontâneas dos estudantes durante $\mathrm{O}$ recreio ou em atividades curriculares complementares. Por isso, pergunta-se: porque a cultura corporal afro-brasileira parece continuar marginalizada na escola? Quais os espaços que são disponibilizados para a sua prática? Essa marginalização seria porque as manifestações culturais afro-brasileiras são vinculadas à festa, à alegria e à ludicidade? Essas manifestações não são adequadas e não possuem a "seriedade" esperada num espaço formal de educação?

\section{A cultura corporal afro-brasileira}

A compreensão de cultura corporal afro-brasileira como fruto da construção de um determinado povo aproxima-se do conceito de corporeidade como corpo vivido, sentido, criador e criação. Segundo Santin (2003), a corporeidade e os estudos do corpo, pela Antropologia, abrangem toda a ação humana. "O gesto e a palavra são os amplificadores do universo significativo, isto é, do universo humano. O corpo e seus movimentos estão sempre no centro de toda e qualquer manifestação e possibilidade expressiva" (SANTIN, 2003, p. 68). Como exemplo de expressividade da cultura corporal afro-brasileira há a dança, a capoeira, o samba e o carnaval.

Pode-se afirmar que as expressões da cultura corporal afrobrasileira são um exemplo da vivência de uma corporeidade plena. Guerra (2008) registra que "[...] o africano canta e dança nos diversos eventos da comunidade a que pertence e das mais variadas 
formas que a criatividade e a espiritualidade lhe concedem, mas especialmente para celebrar a vida!’. Assim, como seria possível a manifestação dessa corporeidade dentro da escola, visto que o tempo, os gestos e atitudes no espaço tendem a serem sempre controlados e pré-determinados?

$\mathrm{Na}$ Educação Física escolar que tem uma tradição no ensino da ginástica e do esporte, como contemplar a plenitude das manifestações da cultura afro-brasileira? Para Daólio (1995, p. 36), "[...] é possível discutir o corpo como uma construção cultural, já que cada sociedade se expressa diferentemente por meio de corpos diferentes". Eis uma questão para a educação física, como tratar no espaço escola as diversidades culturais corporalmente vivenciadas por nossos estudantes?

Nesta pesquisa, procurou-se compreender quais são as manifestações da cultura corporal afro-brasileira vivenciadas na escola e fora da escola pelos estudantes do Ensino Médio. Para Guerra (2008), a cultura corporal africana manifesta-se na "[... dança, corpo, movimento, sons, ritmos, palavras, contagiando e penetrando no seu eu e nos outros seres a sua volta, o ímpeto mais sublime de 'energia vital' que no Brasil é chamado de Axé”. As manifestações mais conhecidas da cultura corporal afro-brasileira são a capoeira, o carnaval e os rituais religiosos, sendo que todas envolvem a dança, o canto, o jogo, a música, e sempre repletos de espiritualidade. Nesse estudo compreende-se a cultura afro-brasileira como a dança, a capoeira, o samba e o carnaval, divisão somente didática, visto que tais manifestações estão presentes: música, corpo e ritmo.

\section{a) A dança afro-brasileira}

A dança, como manifestação cultural, faz parte da história da humanidade. Em todos os registros históricos encontra-se a presença da dança em rituais religiosos, festas populares, nas atividades sociais de salão e em manifestações artísticas ou de espetáculos. Na cultura afro-brasileira encontra-se a dança presente em todos os espaços de sua manifestação. Nos momentos 
litúrgicos, nas festividades populares, nos salóes e nos palcos, pode-se dizer que a dança afro-brasileira é uma transcendência dos rituais religiosos de culto aos orixás. No entanto, não se pode confundir dança afro-brasileira presente nos rituais, com dança artística afro-brasileira, que muitas vezes se inspiram em rituais. Para Souza (2000, p. 305),

No candomblé as danças são caracterizadas pela função que exercem de não impressionar o público, mas de demonstrar um sentido para a vida terrena através da síntese dos gestos e movimentos dos orixás. Já na dança afro, uma boa parte de seu conteúdo e da sua forma sofre considerável criatividade para causar impressão e, quando os mitos são representados e interpretados por um solista, isto é, um único dançarino-ator em cena, a dança poderá ser executada por improvisos.

Nesse excerto, encontram-se algumas características da cultura afro, como a criatividade, a valorização da ritualidade e a presença corporal plena. Diante dessas características como a Educação Física pode incluir a dança afro-brasileira na escola?

Além das danças artísticas, existem as danças midiatizadas e comercializadas, como o "axé". Para Silveira, Cardoso e Sabbag (2008, p. 4), os

“[...] dançarinos de axé possuem uma visão mais voltada à exposição corporal, de realizar movimentos perfeitos, mostrando seu corpo, também perfeito e sempre voltados à sensualidade, costumam chamar a atenção através da forma de atuar com seu corpo".

Ao trazer essa reflexão, propõe-se um debate sobre a corporeidade no espaço escolar. Como um local que historicamente valoriza a racionalidade, a disciplina e a cultura escrita (FREIRE, 1987) pode resgatar a cultura corporal afro-brasileira repleta de alegria e de liberdade?

\section{b) A capoeira}

A Capoeira é uma manifestação da cultura afro-brasileira (FALÇÃO, 1994; SOUZA, 2005) que se caracteriza como um misto de dança, de luta e de jogo e, hoje, é uma marca cultural 
brasileira. A capoeira não é expressão de um único movimento, ela manifesta-se pelo menos em três vertentes: a Capoeira Angola, a Capoeira Regional e a Capoeira Contemporânea.

Conforme Castro Junior (2004), a capoeira possui duas características que ele chama de historicidade, no sentido que a capoeira é fruto de uma construção social e histórica do povo oprimido de origem africana, enquanto: "A ancestralidade, de maneira geral, é considerada relativa aos antepassados, aos antecessores, aos que passaram e aos que se encontram presentes" (CASTRO JUNIOR, 2004, p. 149).

Os praticantes da Capoeira Angola reivindicam a herança dos primeiros "capoeiras" e tem, no Mestre Pastinha ${ }^{2}$, o seu principal representante. Para Lussac e Tubino (2009, p. 11), o surgimento da Capoeira Angola "[...] seria uma oposição às mudanças na capoeira realizadas por $\mathrm{Bimba}^{3}$, somadas às reivindicações socioculturais e identitárias de seus praticantes”.

A Capoeira Angola caracteriza-se pelos instrumentos ${ }^{4}$, seus toques, as cantigas, a organização da roda. Quando se ensinam os toques, os movimentos e o jogo de Capoeira Angola é possível viajar no tempo e vivenciar a luta dos primeiros negros que vieram da África para trabalhar como escravo, principalmente nas plantaçôes de cana e cacau no nordeste brasileiro. Com o objetivo de libertar-se da escravidão, o negro criou uma luta que possibilitava a defesa no momento da fuga e na luta contra os seus senhores.

Segundo Castro Junior (2004, p. 147), "na roda de capoeira, não se canta por cantar: o canto tem sentido e significado. E o cantador canta a partir do jogo”. Os cantos, geralmente são

2 Mestre Pastinha (1889-1981), principal defensor da Capoeira Angola, criou, nos anos 1940, em Salvador, uma escola de capoeira com o objetivo de preservar os fundamentos originais da capoeira.

3 Mestre Bimba (1899 - 1974) construiu, sistematizou um método de ensino de capoeira, introduzindo, na capoeira, movimentos de outras lutas, denominando esse estilo de Capoeira Regional Baiana. Foi o fundador da primeira academia de capoeira do Brasil.

4 Os instrumentos que compóem a bateria são três berimbaus, três caxixis (chocalho), dois pandeiros, um reco-reco, um agogô e um tambor. 
compostos de três momentos: a ladainha, a louvação e o corrido. A ladainha é quando o capoeirista, geralmente o mais experiente e que toca o 'gunga', conta uma história, falando das aventuras ou homenageando algum mestre. O conteúdo de uma ladainha corresponde a uma oração longa e desdobrada pelo cantador em versos, entremeados pelo refrão, repetido pelo coro. As ladainhas, exclusivas do jogo de Angola, são cantadas antes do início do jogo.

A roda da Capoeira Angola tem seu cerimonial; primeiro, organiza-se a bateria, o mestre ou o professor assume o 'gunga'5 e convida alguns dos participantes para inicialmente fazer parte da bateria. Os demais participantes posicionam-se ao lado da bateria formando uma roda, quem participa da roda fica sentado ou agachado esperando a vez de jogar. Os movimentos na Capoeira Angola são realizados, inicialmente, de forma lenta e no final mais acelerado, todos partem do movimento básico que é a ginga. Durante um jogo, realizam-se movimentos como ginga, meia-lua, rabo de arraia, martelo de chão, chapa, tesoura, rasteira, aú, chamadas, entre outros.

A Capoeira Regional caracteriza-se, como o próprio nome diz, pela região onde a capoeira foi transformada e adaptada ao meio sociocultural em que é praticada. Lussac e Tubino (2009, p. 11) afirmam que a capoeira regional surgiu na Bahia no início do século XX:

[...] o próprio nome Regional teria sido dado em oposição ao Nacional, utilizado para a denominação da prática esportiva da capoeira no Rio de Janeiro naquele período, no intuito de se desvencilhar da carga pejorativa que o termo capoeira ainda carregava, e assim obter uma melhor aceitação.

Esse movimento de capoeira nacional que ocorreu no Rio de Janeiro influenciou a criação da Capoeira Regional Baiana, organizada pelo Mestre Bimba. Para Lussac e Tubino (2009), Mestre Bimba criou também um método, chamado curso de capoeira regional baiana. Mestre Bimba, para desenvolver seu

5 O gunga é o berimbau com cabaça maior e com som mais agudo, quem toca o gunga é quem deve comandar a roda. 
método, introduziu golpes de outras lutas, acrescentando treinamento de defesa pessoal.

A roda da capoeira regional é muito parecida com a da Capoeira Angola, diferenciando-se basicamente pelos toques mais acelerados, os participantes em geral permanecem em pé, cantam e acompanham o ritmo com palmas. A Capoeira Regional destacase pela velocidade dos movimentos, identificação hierárquica através de cordéis ${ }^{6}$, contato físico e um processo de ensino muito próximo das demais artes marciais, ensinadas nas academias.

A terceira forma de manifestação é a Capoeira Contemporânea que se caracteriza por suas apresentaçôes, acrobacias e incorpora movimentos tanto da capoeira regional como da angola. Esse movimento tem repercussão internacional, não sendo uma prática restrita ao Brasil, principalmente porque os mestres brasileiros buscaram espaços fora do país, como na Europa e nos Estados Unidos. Sendo assim, a Capoeira Contemporânea sofre adaptações do capoeira, de acordo com o contexto onde se joga.

\section{c) O samba e o carnaval}

O samba e o carnaval são expressões da cultura afrobrasileira que têm grande significado nacional e internacional. Samba, para Lopes (2005, p. 1),

[...] entre os quiocos (chokwe) de Angola, é verbo que significa 'cabriolar, brincar, divertir-se como cabrito'. Entre os bacongos angolanos e congueses o vocábulo designa 'uma espécie de dança em que um dançarino bate contra o peito do outro'. E essas duas formas se originam da raiz multilinguística semba, rejeitar, separar, que deu origem ao quimbundo di-semba, umbigada elemento coreográfico fundamental do samba rural, em seu amplo leque de variantes, que inclui, entre outras formas, batuque, baiano, coco, calango, lundu, jongo etc.

O brincar num ritmo poderia ser a expressão que aproxima o samba brasileiro e, em particular, que dá origem ao carnaval

6 Cordel, na capoeira, é uma corda trançada, em cores que identifica o grupo de capoeira e o nível de hierárquico dos participantes. 
com uma folia popular, uma festa que ultrapassa os atuais desfiles de Escolas de Samba.

No Carnaval, também está presente o afoxé, que é a expressão de rua dos adeptos do candomblé, onde se aproxima a religiosidade nos festejos populares. Para Lopes (2005, p. 3),

O afoxé, cordão carnavalesco de adeptos da tradição dos orixás, e por isso outrora também chamado 'candomblé de rua', apresenta-se cantando cantigas em iorubá, em geral relacionadas ao universo do orixá Oxum. Esses cânticos são tradicionalmente acompanhados por atabaques do tipo 'ilu', percutidos com as mãos, além de agogôs e xequerês, no ritmo conhecido como 'ijexá'.

Carnaval de Escolas de Samba, que também teve sua origem nos terreiros de cultos aos orixás, atualmente sofre influências no âmbito governamental e da indústria cultural e turística. Para Lopes $(2005$, p. 6), o carnaval que conhecemos sofreu diversas influências, para ele

[… a ingerência governamental já não era tão forte, pelo menos enquanto cerceamento da liberdade na criação dos temas, um outro tipo de interferência começava a nascer: a dos cenógrafos de formação erudita ou treinados no show-business, criadores desses enredos, os quais imprimiram ao carnaval das escolas a feição que ele hoje ostenta e que, direta ou indiretamente, selaram o destino dos sambas-enredo.

Sendo assim, resta perguntar como os estudantes vivenciam o carnaval? Eles participam de desfiles de escolas de samba? Eles gostam de samba? Em que momentos o samba é vivenciado na escola?

As manifestações da cultura corporal afro-brasileira são difundidas nos meios de comunicação e vivenciadas em diversos espaços. No entanto, o que se observa é um processo de desportivização das expressões culturais, como exemplo disso, são os festivais de danças, os concursos de escolas de samba e a tentativa de transformar a capoeira em um esporte olímpico. Entende-se por desporitivização (Bracht, 1992) a transformação e a regulamentação das manifestações culturais dentro da 
lógica competitiva, que busca a padronização dos movimentos, a especialização, o recorde e a consagração do vencedor.

A dança afro-brasileira, a capoeira e o carnaval com origem na cultura popular são expressões corporais repletas de alegria e de brincadeira e que, talvez por isso, têm dificuldades de serem trabalhadas na escola. A escola historicamente é local da cultura erudita, dos saberes científicos e das belas artes, os quais são considerados como "superiores" ao senso comum ou saberes populares. O próprio fato de a cultura afro-brasileira estar vinculada aos povos oprimidos pode ser motivo de rejeição, visto que, segundo Freire (1987), se valoriza sempre os saberes do opressor enquanto possuidor de um patrimônio cultural dominante.

\section{Resultados}

O que motivou realizar uma investigação junto aos estudantes de Ensino Médio do Colégio de Aplicação no que se refere à cultura corporal afro-brasileira foi a vivência como professor de Educação Física e as reflexões referentes à rejeição dos estudantes do Ensino Médio pela prática da capoeira na escola.

No Colégio de Aplicação da UFRGS, os estudantes do Ensino Médio podem escolher, trimestralmente, para as aulas de Educação Física, quatro atividades que são oferecidas conforme a disponibilidade de espaços e os conhecimentos dos professores. Como exemplo, a cada trimestre são oferecidas para escolha atividades como futebol, voleibol, handebol, ginástica, dança, capoeira, rugby, rapel e tirolesa, lutas, jogos, entre outras. Desde 2007, tem-se oferecido a capoeira como opção, entretanto, durante todo esse período, a capoeira foi escolhida apenas em um trimestre. As atividades mais procuradas são futebol, voleibol, handebol, basquetebol, ginásticas e, eventualmente, os alunos optam por outras atividades.

Além de o Colégio de Aplicação oferecer como opção a prática de capoeira, ele possui um "projeto de capoeira" no turno 
da tarde, onde participam (CORRÊA; LOUREIRO; DORNELES, 2010) estudantes do Colégio de Aplicação e das comunidades circunvizinhas do Campus do Vale da UFRGS. Observa-se que nesse projeto estão basicamente crianças de cinco a 12 anos. A ausência de adolescentes é outra justificativa para se conhecer as vivências em cultura afro-brasileira dos estudantes do EM.

Como resultado do estudo, identificou-se: a) o perfil dos sujeitos da pesquisa, b) as áreas de conhecimentos que trabalham a cultura afro-brasileira na escola, c) as vivências na cultura corporal afro-brasileira e c) propostas para trabalhar mais efetivamente a cultura corporal afro-brasileira na escola.

\section{a) O perfil dos sujeitos da pesquisa}

Participaram do estudo 49 estudantes do Ensino Médio, na faixa-etária de 16 a 19 anos, dos quais $69,4 \%$ ingressaram no Colégio de Aplicação no Ensino Fundamental e 30,6\% no Ensino Médio, o que permite constatar que a cultura afro-brasileira vivenciada na escola deu-se basicamente no Colégio de Aplicação.

Entre os sujeitos, 21 são do sexo masculino e 28 do sexo feminino, 15 frequentavam o primeiro ano; três, o segundo ano, e 31, o terceiro ano do Ensino Médio. Quanto à cor, 41 declararam cor branca; três, preta; três, parda; um, amarela, e um, indígena. Numa questão subsequente, perguntou-se se existia parentesco direto (pais ou avós) com pessoa afrodescendente (preto ou pardo). 28 estudantes responderam que sim, correspondendo a $57 \%$ dos sujeitos da pesquisa. Esse foi um dado significativo no que se refere à origem étnica dos sujeitos da pesquisa. Quanto à religião, 27 são católicos, seis espíritas, dois evangélicos, dois umbandistas, quatro sem religião, e oito não responderam.

Ao analisar o perfil dos sujeitos da pesquisa, observa-se que, quanto à cor, $6 \%$ são de cor preta e $6 \%$ são de cor parda. Comparando esses percentuais com o Censo de 2010 (IBGE, 2012), nota-se que eles aproximam-se da realidade portoalegrense, pois segundo o censo, a "[...] população residente em domicílios particulares ocupados - Cor ou raça", em Porto 
a Alegre é de 1.396.109. Destes, 79,27\% são brancos, 10,19\% são de cor preta e 10,02\% são parda, enquanto 0,29\%, amarela e $0,23 \%$ são indígenas.

\section{b) Áreas de conhecimentos que trabalham a cultura corporal afro-brasileira na escola}

O Colégio de Aplicação é organizado em quatro departamentos: Departamento de Expressão e Movimento, que reúne as áreas de conhecimentos de Educação Física, Educação Musical, Artes Visuais e Teatro; Departamento de Comunicação, que reúne Língua Portuguesa, Literatura e Línguas Estrangeiras; Departamento de Humanidades que reúne História, Geografia, Filosofia e Sociologia, e o Departamento de Ciências Exatas e da Natureza que reúne Química, Física, Biologia e Matemática.

Como resultado do estudo, observa-se que a cultura afrobrasileira é tratada na escola pelo Departamento de Humanidades, sendo que 87,7\% declararam ter estudado a história da cultura afro-brasileira nas áreas de conhecimentos de História, Geografia e Sociologia. Outros dois Departamentos são lembrados por tratarem da cultura afro-brasileira: o Departamento de Comunicação, 16,3\% afirmam que a área de Língua Estrangeira enfocou a cultura afro-brasileira; e o Departamento de Expressão e Movimento, 8,2\% afirmam que trataram da cultura afrobrasileira nas áreas de Música e Educação Física.

Esse baixo índice de indicação dos estudantes no que se refere à cultura corporal afro-brasileira, quando apenas 8,2\% afirmam que a área de Educação Física trabalha com a cultura afro-brasileira, de certa forma, refere-se à existência do projeto de Capoeira oferecido pela área (CORRÊA; LOUREIRO; DORNELES, 2010). Quanto à área de música, também se registra o mesmo caráter visto que a área ofereceu oficinas de percussão e de choro $^{7}$ (BRAGA; BARCH, 2008).

7 Estilo musical que faz uma mistura das músicas portuguesas com a música afrobrasileira. 


\section{c) Vivências dos estudantes na cultura corporal afro- brasileira}

Como resultado da pesquisa, identificaram-se as vivências na cultura corporal nos diversos espaços escolares e fora da escola, além de verificar as vivências na cultura corporal afro-brasileira. Para fazer esse diagnóstico, perguntou-se: Quais experiências você possui na cultura corporal de movimento (danças, lutas, jogos, ginástica, esportes)?

Como resultados, obteve-se: $32,6 \%$ não responderam a questão; 26,6\% relatam ter experiência com esporte; 10,2\% informam ter experiência em dança; $10,2 \%$ relatam ter experiência em ginásticas; 6,1\%, experiência em lutas, e 6,1\%, experiência em jogos. Esses dados, mesmo que muitos não tenham respondido, correspondem às pesquisas anteriores (CORREA; MORO, 2004; CORRÊA; BARAN; MENEGUIZZI, 2005), que apontam a predominância das atividades esportivas nas práticas da cultura corporal na escola.

Quando se perguntou sobre as vivências na cultura corporal afro-brasileira na escola e fora da escola, obtiveram-se os seguintes resultados: a) na escola, 6,2\% afirmam terem vivência em dança afro-brasileira, 8,2\% vivência em capoeira e 91,6\% afirmam não terem vivência na cultura afro-brasileira; b) fora da escola, 10,2 \% afirmam terem vivência em capoeira; 2\%, em dança afro-brasileira; $2 \%$, em desfile de escola de samba, e 89,8\% afirmam não terem vivência na cultura corporal afro-brasileira.

Esses resultados retratam a realidade do ensino da cultura corporal na escola, onde se observa a predominância da influência da cultura europeia e norte americana (SOARES, 1994; BRACHT, 1992), de início com a ginástica e posteriormente, com os esportes, principalmente futebol, voleibol, handebol e basquetebol. Mesmo fazendo mais de 30 anos que no âmbito de Educação Física vem se discutindo a possibilidade de trabalhar a capoeira como uma atividade de luta, própria da cultura corporal afro-brasileira, o que se constata é uma resistência a sua 
prática. Destaca-se a resistência ao ensino de capoeira, visto que ela é oferecida aos estudantes como opção de prática nas aulas de Educação Física ou como atividade no turno inverso.

Outro fator importante relaciona-se ao descaso com a cultura afro-brasileira na formação de professores de Educação Física, que historicamente foi pautada pelos estudos de biologia, anatomia, fisiologia, esportes, ginásticas, atletismo, natação, entre outros (QUELHAS; NOZAKI, 2006). Somente após a reestruturação curricular os cursos de Educação Física no início do século XXI é que se tem discutido uma formação sólida no campo da cultura corporal.

Até então o que se observa é a valorização da cultura europeia e norte-americana em detrimento da cultura brasileira, principalmente no que se refere à capoeira, visto que ela surge entre os excluídos sociais e no decorrer de sua história, torna-se resistência à sociedade, primeiramente capitalista escravocrata e, posteriormente, liberal capitalista. Como símbolo de resistência à capoeira cria códigos e possui um ritmo diferente da Educação Física escolar.

Segundo Bracht (1992), a Educação Física escolar historicamente adota uma ordem esportiva pautada por disciplina, autoridade, concorrência, rendimento, racionalidade técnica, organização e burocracia. Sendo assim, a capoeira terá dificuldade de adaptar-se a esse espaço, pois para Santos (2005, p. 87), "[... a capoeira traz no seu bojo determinadas ideias que podem se confrontar com o cotidiano de muitas escolas e com as pedagogias dos professores". Para o autor, a capoeira possui algumas características, sendo que a sua ordem interna "[...] pode significar a 'desordem' da organização escolar ou a formação de outra ordem na instituição e nas aulas de Educação Física”. Nesse sentido, indaga-se: como possibilitar a prática da cultura corporal afro-brasileira na escola? 


\section{d) Propostas dos estudantes para trabalhar a cultura afro- brasileira na escola}

Ao perguntar sobre como pode ser trabalhada na escola a cultura afro-brasileira, obteve-se o seguinte resultado: $24,5 \%$ dizem que não sabem responder; $43,8 \%$ propõem o oferecimento de oficinas e palestras com liberdade de escolha, e 32,6\% sugerem que se ensine nas aulas de Educação Física capoeira e dança afro-brasileira. As respostas dos estudantes demonstram que permanece a não valorização ou o desconhecimento de que a cultura corporal afro-brasileira deva ser trabalhada, pelo menos, nas aulas de Educação Física.

Os $32,6 \%$ dos que propóem a prática representam a quantidade média que opta pela prática da capoeira durante as escolas semestrais. Frequentemente, durante as escolhas das atividades trimestrais, um número pequeno de estudantes tem optado pela capoeira, no entanto, não se atinge o número suficiente para a oferta da atividade. Como se deve escolher entre as quatro modalidades mais votadas, a capoeira é sempre excluída. A proposta mais indicada são oficinas, atividades curriculares optativas ou eletivas que podem ser oferecidas a cada semestre aos estudantes do Ensino Médio.

Ao defenderem a oferta como atividade eletiva, os estudantes demonstram que a escola pode oferecer essa atividade, desde que não seja obrigatória. Com isso, evidenciam certa resistência à cultura corporal afro-brasileira, favorecendo outras manifestações culturais e esportivas predominantes no Brasil, como o futebol e o voleibol. Pode-se afirmar que tudo que é exterior, oriundo de outras culturas têm mais valor do que o que é nosso. Nesse aspecto, pode-se referir o que Freire (1987) define como o oprimido que introjeta o opressor, percebendo-se incapaz. Nessa condição, o sujeito "incapaz" exerce sobre si mesmo o poder do opressor. Para o sujeito oprimido e "hospedeiro" do opressor, "[...] ser é parecer e parecer é parecer com o opressor" (FREIRE, 1987, p. 32). Nesse sentido, o correto, o verdadeiro 
e o próprio ser são aquilo que o opressor é. Sendo assim, é nesse processo interiorizado que o exercício do poder ocorrerá: eu, como oprimido, um não ser, devo pensar, agir, situar-me no mundo como desprovido de poder, como o opressor já outrora prescreveu. Tudo que vem do opressor é bom. Como resultado dessa analogia, a cultura estrangeira ou "eurocêntrica" deve ser valorizada em detrimento da cultura brasileira.

Com essas constatações é possível pensar que em determinados momentos, a inclusão da cultura corporal afro-brasileira deve ser obrigatória, possibilitando a sua aprendizagem e provocando a reflexão crítica de sua ausência, até então no currículo escolar. Porque nós optamos em vivenciar as expressões culturais dominantes ou próprias dos opressores, na concepção freiriana, em detrimento da nossa cultura?

\section{Considerações Finais}

Ao diagnosticar as áreas de conhecimento que tratam da cultura afro-brasileira e as vivências dos alunos do Ensino Médio na cultura corporal afro-brasileira, destacou-se a resistência à referida cultura na escola. Observou-se que o ensino da história e da cultura afro-brasileira está presente como conteúdo das áreas de conhecimentos de História, Geografia, Sociologia e Filosofia. O relato dos estudantes confirma isso, entretanto quanto à cultura corporal, pode-se afirmar que é pouco trabalhada na escola, o que de certa forma, é preocupante, pois segundo Freire (1996, p. 38), "[...] ensinar exige a corporificação das palavras pelo exemplo". Nesse sentido, corporificar seria a vivência da cultura afro-brasileira na escola.

Como consignar que a cultura afro-brasileira é importante, se ela não é corporificada ou vivenciada no cotidiano escolar? A Educação Física escolar tem uma dívida com tal cultura que foi negligenciada $\mathrm{em}$ nome de uma prática voltada à melhoria das condições de saúde através da Educação Física "higienista”, hoje, 
renovada através do discurso de promoção de saúde e da prática esportiva (CORRÊA; MORO, 2004).

Além do discurso "higienista", existe a predominância do ensino de esportes de origem europeia e norte-americana, principalmente, aqueles veiculados pelos meios de comunicação de massa e que, de certa forma, são corresponsáveis pela "invasão cultural”. Conforme Freire (1988, p. 149), “[...] a invasão cultural é a penetração que fazem os invasores no contexto cultural dos invadidos, impondo a estes sua visão de mundo, enquanto lhes freiam a criatividade, ao inibirem sua expansão". Para lutar contra esse processo de invasão é preciso promover ações efetivas que busquem a valorização da cultura popular, no caso da Educação Física, valorizar a cultura corporal afro-brasileira é resgatar a história e a dignidade dos povos de descendência africana que compõem a população brasileira.

A resistência dos estudantes talvez seja motivada pelo apelo dos meios de comunicação de massa aos outros esportes, no entanto, muitos estudantes demonstram a preocupação com a cultura afro-brasileira ao proporem a inclusão da dança e da capoeira nas aulas de Educação Física ou através de uma disciplina eletiva. Assim, como início da reflexão sobre a cultura corporal afro-brasileira, o Colégio de Aplicação, como dispõe em sua organização curricular disciplinas eletivas, possa oferecer tempo e espaço para essa manifestação cultural. Porém, essa é uma peculiaridade do Colégio de Aplicação, enquanto para as demais escolas, seria necessária a inclusão como atividade da Educação Física escolar obrigatória.

Parece que não basta oportunizar aos estudantes a escolha da prática ou não da cultura afro-brasileira, talvez não se avance porque há o risco de não ir além do senso comum. Historicamente, entendem-se como atividades próprias da Educação Física, jogos, ginásticas, esportes e essas atividades são trabalhadas tanto na escola, quanto na formação profissional dos professores de Educação Física. Como superar o senso comum e incluir atividades da cultura afro-brasileira na escola? Segundo Corrêa e Moro 
(2004, p. 279), para transformar ou superar esse senso comum, compete aos professores de Educação Física mobilizarem-se “[... para construir uma prática curricular que tenha certa estruturação e uma programação coerente com os objetivos sociais”. Assim, ao objetivar ensinar a cultura afro-brasileira na escola, não é suficiente oferecê-la como opção de escolha, mas como atividade curricular obrigatória.

\section{Referências}

BRACHT, Valter. Educação Física e aprendizagem social. Porto Alegre: Magister, 1992.

BRAGA, Reginaldo Gil; BARTH, Cássio Dalbem. Pesquisadores Educadores ou Educadores Pesquisadores? Uma experiência de pesquisa e ação pedagógica participativa na Oficina de Choro do Colégio de Aplicação da UFRGS. In. Anais. XVIII Congresso da Associação Nacional de Pesquisa e Pós-Graduação (ANPPOM), Salvador - 2008. Disponível em: <http://www.anppom.com.br/anais/anaiscongresso_anppom_2008/ comunicas/COM473\%20-\%20Braga\%20et\%20al.pdf $>$. Acesso em: 21 mar. 2012.

BRASIL. Lei n ${ }^{\circ}$ 9.394, de 20 de dezembro de 1996. Estabelece as diretrizes e bases da educação nacional. Portal Ministério da Educação. Disponível em: <http://www.planalto.gov.br/ccivil_03/Leis/L9394.htm>. Acesso em: 24 jan. 2009.

BRASIL. Lei $n^{\circ} 11.645$, de 10 de março de 2008. Estabelece as diretrizes e bases da educação nacional, para incluir no currículo oficial da rede de ensino a obrigatoriedade da temática. História e Cultura Afro-Brasileira e Indígena. Portal Ministério da Educação. Disponível em: <http://www. planalto.gov.br/ccivil_03/_Ato2007-2010/2008/Lei/L11645.htm\#art1>. Acesso em: 14 ago. 2009.

BRASIL. Lei no 10.639, de 20 de dezembro de 1996, que estabelece as diretrizes e bases da educação nacional, para incluir no currículo oficial da Rede de Ensino a obrigatoriedade da temática "História e Cultura AfroBrasileira", e dá outras providências. Portal Ministério da Educação. 
Disponível em: <http://www.planalto.gov.br/ccivil_03/Leis/L9394.htm>. Acesso em: 24 jan. 2009.

CASTRO JÚNIOR, Luis Vitor. Capoeira angola: olhares e toques cruzados entre historicidade e ancestralidade. In. Revista Brasileira de Ciências do Esporte, Campinas, v. 25, n. 2, p. 143-158, jan. 2004.

CORRÊA, Ivan Livindo de Senna; BARAN, Gabriele; MENEGUZZI, Jaqueline Maira. O conhecimento em educação física dos egressos do ensino fundamental videirense. In: IV Seminário de Iniciação Científica da Unoesc. Joaçaba: Unoesc, 2005. v. 1, p. 94-94.

CORRÊA, Ivan Livindo de Senna; LOUREIRO, Renata Gomes; DORNELES, Jean Carlo. Capoeira: a cultura corporal afro-brasileira como perspectiva de inclusão social. In: $29^{\circ}$ Seminário de extensão universitária da região sul (SEURS), 2010, Foz do Iguaçu-PR. Anais do $29^{\circ}$ SEUS. Foz do Iguaçu: Unioeste, 2010. CD-ROM.

CORRÊA, Ivan Livindo de Senna; MORO, Roque Luiz. Educação Física Escolar: reflexão e ação curricular. Ijuí: Editora Unijuí, 2004.

DAÓLIO, Jocimar. Da cultura do corpo. Campinas: Papirus, 1995.

DUARTE, Marcelo. Guia dos curiosos: esportes. 3. ed. São Paulo: Panda Books, 2006.

FALCÃO, José Luiz Cirqueira. Capoeira. In: KUNZ, Elenor (Org.). Didática da Educação 1. Ijuí: Editora Unijuí, 1998.

. O jogo da capoeira em jogo. In: Revista Brasileira de Ciências do Esporte, Campinas, v. 27, n. 2, p. 59-74, jan. 2006.

FERREIRA, Aurélio B. de Hollanda. Dicionário Aurélio Eletrônico Século XXI. Rio de Janeiro: Nova Fronteira, 1999.

FODDY, William. Como perguntar: teoria e prática da construção de perguntas em entrevistas e questionários. Oeiras: Celta Editora, 1996.

FREIRE, Paulo. Pedagogia do Oprimido. 17 ed. Rio de Janeiro: Paz e Terra, 1987.

. Pedagogia da Autonomia. Rio e Janeiro: Paz e Terra, 1996.

GUERRA, Denise. Um olhar sobre a cultura corporal de movimento afrobrasileira construída a partir da corporeidade africana. In: Revista África e Africanidades - Ano I - n. 2 - agosto. 2008. 
IBGE. Censo demográfico 2010: características da população e dos domicílios: resultados do universo. Disponível em: <http://www.ibge. gov.br/cidadesat/topwindow.htm?1>. Acesso em: 20 mar. 2012.

KUNZ, Elenor. (Org.). Didática da Educação 1. Ijuí: Editora Unijuí, 1998. Unijuí, 1994.

. Transformação didático-pedagógica do esporte. Ijuí: Editora

LOPES, Nei. A presença africana na música popular brasileira. In: Revista Espaço Acadêmico. n. 50. julho\2005. p. 1-9

LUSSAC, Ricardo Martins Porto; TUBINO, Manoel José Gomes. Capoeira: a história e trajetória de um patrimônio cultural do Brasil. In: Revista da Educação Física/UEM Maringá, v. 20, n. 1, p. 7-16, 1. trim. 2009.

MARINHO, Inezil Pena. Subsídios para o estudo da metodologia do treinamento da capoeiragem. Rio de Janeiro: Imprensa Nacional, 1945.

MUNDSTOCK, Elsa et al. Introdução à análise estatística: utilizando o SPSS 13.0. Cadernos de Matemática e Estatística. Porto Alegre: Instituto de Matemática da UFRGS, 2006.

QUELHAS, Álvaro de Azeredo; NOZAKI, Hajime Takeuchi. A formação do professor de educação física e as novas diretrizes curriculares frente aos avanços do capital. In: Motrivivência, Ano XVIII, n. 26, jun. 2006.

SANTIN, Silvino. Educação Física: uma abordagem filosófica da corporeidade. 2. ed. Ijuí: Editora Unijuí, 2003.

SANTOS, Gilbert de Oliveira. Da Capoeira e a Educação Física. 2005. (100f.). Dissertação (Mestrado em Educação) - Universidade Estadual de Campinas, Faculdade de Educação. Campinas, 2005.

SILVA, Tomaz Tadeu da. O que produz e que reproduz em educação: ensaio de Sociologia da Educação. Porto Alegre: Artes Médicas, 1992.

SILVEIRA, Rozana Aparecida; CARDOSO, Fernando Luiz; SABBAG, Samantha. Relações de gênero e relação corporal entre praticantes de axé e hip hop. In: Anais. Seminário Internacional Fazendo Gênero 8. (Florianópolis, de 25 a 28 de agosto de 2008). Disponível em: <http:// www.fazendogenero.ufsc.br/8/sts/ST22/Silveira-Cardoso-Sabbag_22. pdf $>$. Acesso em: 20 fev. 2011. 
SOARES, Carmen Lúcia et al. Metodologia do Ensino de Educação Física. São Paulo: Cortez, 1992.

. Educação Física: raízes européias de Brasil. Campinas: Autores Associados, 1994.

SOUZA JUNIOR, Marcílio. et al. Coletivo de autores: a cultura corpora em questão. In: Revista Brasileira de Ciências do Esporte. Florianópolis, v. 33. n. 2, p. 391-411, abr./jun. 2011.

SOUZA, Edilson Fernandes. Etnografia e história da dança litúrgica e artística no Rio de Janeiro. In: Anais. VII Congresso brasileiro de história da Educação Física, esportes, lazer e dança (Gramado-RS). Porto Alegre: UFRGS $\backslash E S E F$, 2000. p. 304-308. 